\title{
$\mathrm{PH} 100_{\text {debate }}$
}

a debate Repositorios y redes sociales académicas para la transferencia del conocimiento abierto

| coordina Remedios Melero Melero

\section{Hacia la colaboración entre repositorios y redes sociales académicas}

Javier Sánchez Pérez | Dpto. de Informática y Sistemas, Universidad de Las Palmas de Gran Canaria

URL de la contribución <www.iaph.es/revistaph/index.php/revistaph/article/view/4666>

En marzo de este año, la Universidad de Las Palmas de Gran Canaria (ULPGC) presentó su nuevo repositorio institucional, y parte de su sistema de información para la gestión de la investigación, llamado accedaCRIS. Este proyecto fue liderado por el Vicerrectorado de Investigación, Innovación y Transferencia, y desarrollado junto con la Biblioteca y el Servicio de Informática.

Después de más de dos años y medio de trabajo intenso, se ha logrado implantar un software libre que se ha adaptado a las necesidades de la institución. Este proyecto ha supuesto un reto muy importante, ya que es la primera vez que se ha conseguido recopilar gran parte de la producción científica de los investigadores y sincronizar la información con las bases de datos de la organización y otras fuentes de datos externas.

El éxito de este proyecto ha dependido de muchos factores diferentes y hemos tenido que tratar con problemas de distinta índole, como pueden ser: la dificultad para recopilar los datos de las publicaciones de forma correcta, sobre todo las que no están recogidas en las bases de datos indexadas, y asociarlas convenientemente con sus autores; o la complicación que supone obtener la información de las bases de datos institucionales, que muchas veces no son fácilmente accesibles, no están correctamente organizadas, o la estructura de la información asociada es compleja.

Nuestra plataforma se conecta a varias fuentes de datos externas desde las que obtiene, en su mayor parte, publicaciones y algunas métricas. Esto ha permitido que, en un tiempo razonable, se haya podido recopilar gran cantidad de información sobre lo que se produce en nuestra universidad. Con el tiempo estas aplicaciones se irán conectando a más fuentes de datos, entre las que cabe esperar algunas redes sociales académicas.

Los repositorios permiten visibilizar no solo las publicaciones, sino otro tipo de datos que solo están disponibles en la organización, tales como información concreta de los investigadores, departamentos, grupos e institutos universitarios, así como de los proyectos de investigación, las tesis doctorales, los trabajos fin de título y otros. Las redes sociales no pueden tener acceso a esta información y necesitan que los investigadores la introduzcan manualmente. Es aquí donde los repositorios juegan un papel muy relevante, ya que se requiere una actualización constante de estos contenidos. Por otro lado, a los repositorios les interesa complementar la información de las publicaciones con el número de citas que reciben, o los índices de impacto de las revistas en las que se publican -además de otras métricas-, información que muy difícilmente son capaces de generar con sus propios medios.

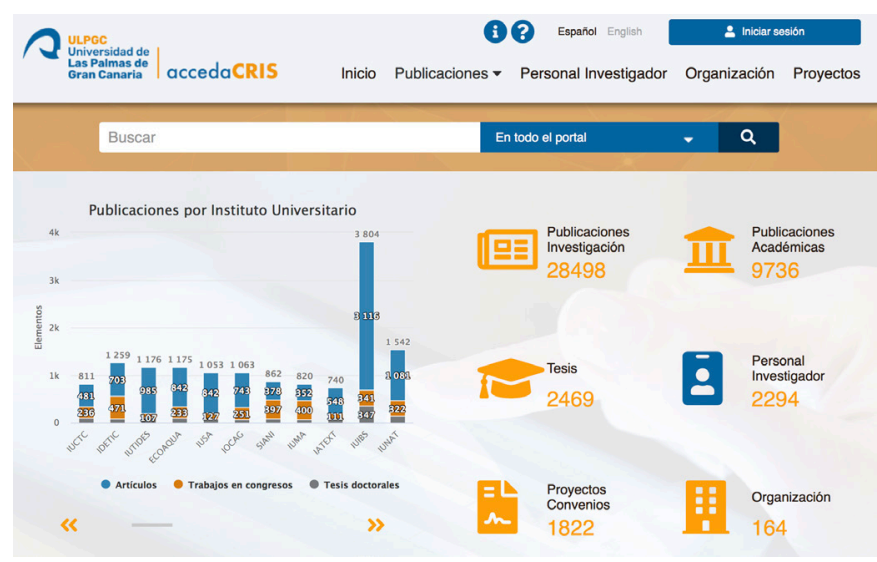

accedaCRIS permite acceder a mucha información sobre la investigación y consultar distintas métricas 
Existe la percepción de que los repositorios son el actor más débil puesto que tienen un carácter local. Sin embargo aportan mucho valor, ya que generan información que de otra forma no puede ser accesible: mientras más información suministren, más necesidad tendrán las redes sociales de contar con ellos.

En este sentido, es interesante que exista una colaboración entre las redes y los repositorios, puesto que se complementan en muchos aspectos. Produce frustración ver cómo las redes obtienen datos de los repositorios mientras que, muchas de ellas, no permiten el acceso a su contenido. De alguna manera debemos promocionar aquellas que sean más abiertas y estén dispuestas a compartir sus datos, como ocurre, en parte, con Google Académico. Es probable que la red social que termine imponiéndose siga los principios y prácticas de la Web 2.0, donde un factor importante es la colaboración entre distintos actores. En cualquier caso, las instituciones públicas deben velar por el correcto registro y difusión del conocimiento. No debe preocuparles que las redes sociales se nutran de este trabajo, sino al contrario, permite cumplir mejor con sus objetivos.

Durante este tiempo, hemos caído en la tentación de imitar lo que hacen las redes, pero creemos que por ese camino estamos abocados al fracaso, ya que no contamos con sus medios ni con su alcance.

Centrarnos en nuestro cometido principal, así como servir de herramienta para poder evaluar el estado de la investigación y contribuir en los procesos internos de gestión de la organización, son claves para el éxito.

Es importante que los investigadores se sientan involucrados en el repositorio de su institución, pero sin que les suponga mucho esfuerzo. Las organizaciones deben articular procesos que faciliten y promuevan esta tarea. Y el investigador debe percibir que merece la pena dedicarle tiempo. Las redes sociales lo consiguen llevando un registro de las citas y las veces que se descargan y leen sus publicaciones. Nosotros hemos sido capaces de aunar las métricas desde distintas bases de datos,

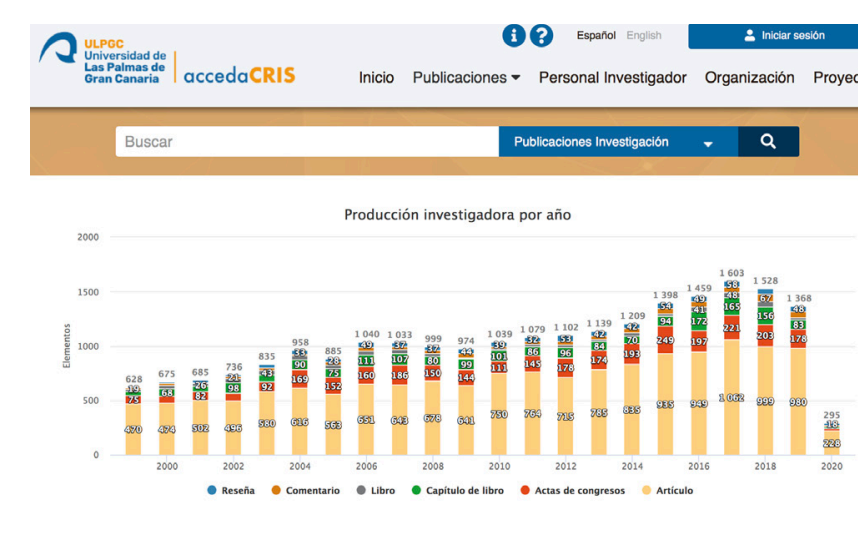

El acceso a bases de datos externas ha permitido recopilar gran parte de la producción científica de la universidad en poco tiempo

con lo que los investigadores pueden acceder a esta información de forma centralizada.

En el futuro, además, sería interesante que hubiera una colaboración entre instituciones para compartir la información. Es habitual ver artículos donde intervienen autores de distintas regiones y países. Estas publicaciones van a estar repetidas en varios repositorios, pero ninguno va a tener toda la información completa, ya que, por ejemplo, cada uno asigna las autorías a sus propios investigadores. Sería conveniente aumentar las capacidades de interoperabilidad entre estas herramientas, de manera que exista una comunicación directa entre los repositorios y se aproveche el esfuerzo realizado entre todos.

En resumen, el coste de implantar, mantener y hacer evolucionar una plataforma como accedaCRIS requiere un trabajo considerable, que debe perdurar en el tiempo y se debe seguir alimentando con información actualizada. Involucrar a los investigadores para que colaboren en la revisión de sus datos también es muy importante, pero tienen que ver la utilidad sin que suponga un gran esfuerzo. Los repositorios institucionales deben conseguir que los datos sean precisos y abarquen la mayor parte de la producción científica. Este objetivo es diferente al de las redes sociales académicas, que están más centradas en ser un vínculo de comunicación entre investigadores y en rentabilizar su uso. El futuro, desde nuestro punto de vista, es la colaboración entre todas las partes. 